\title{
Do governo dos homens... e das almas ${ }^{*}$
}

\author{
CLARICE ANTUNES DO NASCIMENTO \\ Universidade Luterana do Brasil, Canoas, RS, Brasil
}

\section{RESUMO}

$\mathrm{O}$ artigo contempla discussões acerca de um programa de governo que visa à participação da sociedade nas ações e decisões governamentais, estimulando iniciativas de caráter voluntário, solidário e colaborativo. Mais que isso, visa à produção de sujeitos empreendedores e proativos, inseridos numa lógica econômico-solidária que parece ter como objetivo a responsabilização dos sujeitos. Com base nas teorias de Foucault, problematiza-se a hipótese de o Estado estar assumindo um papel compreendido como da Escola — o de educador -, na medida em que se utiliza de estratégias que atuam pedagogicamente sobre os indivíduos, produzindo subjetividades. E cogita-se a emergência de um Estado-coach, que assume o papel de estimular as pessoas a alavancarem melhores resultados. Conforme Wolk (2008), o papel do coach é capacitar os outros para que possam obter o máximo de rendimento de suas competências e habilidades.

\section{PALAVRAS-CHAVE}

educação; Michel Foucault; Estado-coach; governamentalidade.

* Artigo recomendado pelo Comitê Científico da 37a Reunião Nacional da Associação Nacional de Pós-Graduação e Pesquisa em Educação (ANPEd) para apreciação da Comissão Editorial da Revista Brasileira de Educação. 


\section{OF THE GOVERNMENT OF MEN... AND SOULS}

\section{ABSTRACT}

This article includes discussions about a government program that aims the participation of society in government actions and decisions, encouraging voluntary, solidary and collaborative initiatives. More than that, it has the objective of producing proactive and entrepreneur individuals, inserted in a solidary and economic logic that seems to be directed towards the responsibility of the subjects. Based on Foucault's theories, we discuss the hypothesis that the State assumes the school's role - the educational one -, considering the use of strategies that act pedagogically on the individuals, producing subjectivities. Besides, we think about the emergence of a coach State, which assumes the role of stimulating people to leverage better results. As Wolk (2008), the coach's role is empower the others in order to obtain the maximum performance of your skills and abilities.

KEYWORDS

education; Michel Foucault; coach-State; governmentality.

\section{DEL GOBIERNO DE LOS HOMBRES... Y DE LAS ALMAS}

\section{RESUMEN}

E1 artículo incluye discusiones acerca de un programa gubernamental dirigido a la participación de la sociedad en las acciones y decisiones del gobierno, fomentando las iniciativas voluntarias, de apoyo y de colaboración. Más que eso, tiene como intento producir individuos y empresarios proactivos, inserta en una lógica económica que parece tener como finalidad la solidaridad y la responsabilidad de las personas. Embasado en las teorías de Foucault, aborda la hipótesis del Estado estar asumiendo un papel entendido como de la escuela - el maestro - en la medida en que utiliza estrategias pedagógicas que actúan sobre las personas, produciendo subjetividades. Y se considera la aparición de un Estado entrenador, que asume el papel de estimular a la gente a aprovechar mejores resultados. Según Wolk (2008), el rol del coach es capacitar a otros para obtener el máximo rendimiento de sus habilidades y capacidades.

educación; Michel Foucault; Estado entrenador; gubernamentalidad. 


\section{INTRODUÇÃO}

Num momento em que vivenciamos, no âmbito sociopolítico, um cenário no qual se verifica o esgotamento financeiro nas mais diversas áreas, exigindo do governo medidas que conflitam com as necessidades da população e exigindo dos cidadãos atitudes proativas e solidárias que contribuam para a superação das dificuldades, este artigo vem problematizar aspectos que em alguma medida remontam características comuns à realidade na qual estamos inseridos.

Trata-se de um trabalho oriundo de pesquisa de mestrado em educação, no qual se busca analisar, justamente, um programa de governo - o Programa de Governança Solidária Local - implantado no município de Porto Alegre/RS no ano de 2005 , por meio do qual se pretendia, entre outros fins, maior aproximação com as comunidades locais, no intuito de estabelecer parcerias para dar conta da solução dos problemas socioeconômicos existentes. A exemplo do que vem ocorrendo no cenário atual, objetivava-se um ambiente de diálogo com a população, porém não tanto um diálogo para abrandar conflitos, mas com vistas à identificação de soluções às causas compreendidas como de legitimidade social.

Almejava-se a participação voluntária da sociedade, bem como a aderência de sujeitos com certo grau de autonomia, senso político e capital intelectual, indispensáveis à tomada de decisões e à proposição de ações que levassem ao desenvolvimento das regiões abrangidas pelo programa. De acordo com Damasceno (s/d., p. 1), "são tempos de grande mobilidade e incerteza, marcados por profundas transformações provenientes do neoliberalismo, da globalização e do avanço tecnocientífico que passaram a regular as relações humanas".

$\mathrm{O}$ que o referido programa propunha era um modo de governar posicionado como "cogestão", ou seja, um tipo de gestão na qual os sujeitos inseridos nas comunidades poderiam atuar em regime de responsabilidade compartilhada. De acordo com Feijó (2008), a Governança Solidária Local seria um novo estilo de governança adotado pela Prefeitura Municipal de Porto Alegre/RS, baseado na democracia participativa e na parceria entre governo e sociedade, que estimula o protagonismo e o empreendedorismo dos cidadãos e sua corresponsabilidade na gestão compartilhada das ações públicas.

Tal propósito, de início, nos remete a duas possibilidades, entre tantas que poderiam ser destacadas: a primeira, a necessidade emergente de se promover um ambiente que favorecesse o diálogo e a parceria que se buscava; a segunda, de se reconhecer as potencialidades dos sujeitos, mostrando o seu pertencimento/reforçando sua identidade local e valorizando os resultados advindos de sua atuação/ participação. Haja vista o objetivo da Governança Solidária Local de "estimular parcerias baseadas nos princípios da participação, autonomia, transversalidade e na corresponsabilidade em favor da inclusão social", fortalecendo a relação sociedade-Estado "em ambiente de diálogo e pluralidade, e estabelecendo relações com a sociedade cada vez mais horizontalizadas" (Prefeitura Municipal de Porto Alegre, 2005a, p. 5). Para tanto, no ano de 2005 criou-se a Secretaria Municipal de Coordenação Política e Governança Local, unidade administrativa que se encarregaria de colocar em prática e gerenciar o Programa de Governança Solidária Local. 
Apresentando-se como "uma rede intersetorial e multidisciplinar que se organiza territorialmente para promover espaços de convivência capazes de potencializar a cultura da solidariedade e cooperação entre governo e sociedade local" (Prefeitura Municipal de Porto Alegre, 2005a, p. 5), a Governança Solidária Local utiliza-se de redes sociais - as Redes de Governança - , por meio das quais passa a gestar a conectividade entre as pessoas, práticas, processos, conhecimentos etc. Mais que isso, por meio das redes teria acesso ao capital humano existente nas comunidades. Na rede tudo se tornaria visível e, portanto, permitiria exercer poder nas mais diversas direções. Um poder que, até mesmo, na mesma medida em que se caracterizaria como ato de controle e regulação também poderia operar estimulando e produzindo formas de ser, pensar e agir.

De acordo com Foucault (2010, p.29), o corpo está "diretamente mergulhado num campo político; e as relações de poder têm alcance imediato sobre ele; elas o investem, o marcam, o dirigem, o supliciam, sujeitam-no a trabalhos, obrigam-no a cerimônias, exigem-lhe sinais". E, estando imersos em um campo político, os corpos não apenas produzem relações, mas são produzidos por elas — isso implica uma relação de força e, portanto, uma relação de poder.

Num cenário em que a busca pela sustentabilidade econômica torna-se cada vez mais latente, os investimentos de poder vão sendo direcionados aos lugares em que se localizam os recursos indispensáveis a sua manutenção. No caso da Governança Solidária Local, o olhar se volta às comunidades, no interior das quais estaria concentrado o aporte de capital humano e social que se tornara recurso estratégico para o atendimento de demandas socioeconômicas que o Estado parece não dar conta de solucionar sozinho.

A Governança Solidária Local, como um programa de governo, foi concebida para a indução e fomento de parcerias entre poder público, comunidade, associações e empresas privadas, utilizando o capital social local de modo que formasse uma rede solidária e cooperativa que viabilizaria ações, projetos e campanhas. Segundo o antropólogo organizacional Ignácio García, da Universidade de Buenos Aires, o termo "capital social" faz referência às redes de relacionamento baseadas na confiança, cooperação e inovação que são desenvolvidas pelos indivíduos dentro e fora da organização, facilitando o acesso à informação e ao conhecimento (García, 2009). Na visão desse autor, o capital social é a mistura que interconecta as várias formas do capital humano, criando o ativo intangível ${ }^{1}$ mais valioso: as redes humanas de trabalho.

E, num ambiente em que se acredita, conforme aponta Feijó (2008, p. 27), que "o caminho para o fortalecimento da democracia passa, indubitavelmente, pela Responsabilidade Social”, a busca de parcerias depende de atitudes e espíritos de solidariedade, cooperação, protagonismo, participação e cidadania, da mesma forma que o estímulo ao empreendedorismo torna-se estratégico para a promoção e dinamização de iniciativas e ações que pudessem alavancar o desenvolvimento

1 Para Hoss et al. (2010), ativos intangíveis são incorpóreos representados por bens e direitos associados a uma organização. Independentemente de estarem contabilizados, possuem valor e podem agregar vantagens competitivas, tal como é o caso de uma marca. 
sustentável no âmbito local e municipal. E, sendo uma necessidade política, quem acaba assumindo esse papel é a própria Governança Solidária Local, que passa, por um lado, a investir em espaços e projetos de capacitação com vistas a municiar os sujeitos com ferramentas ditas "apropriadas" à gestão participativa, e, por outro, a reconhecer e fazer ver as potencialidades individuais e coletivas que poderiam ser utilizadas no atendimento das demandas apresentadas pela própria comunidade onde os sujeitos estariam inseridos.

Conforme consta na cartilha da Governança Solidária Local (Prefeitura Municipal de Porto Alegre, 2005b, p. 9), um dos documentos utilizados na disseminação do programa, "toda pessoa poderia cooperar, aportando novos recursos, novas habilidades, assumindo responsabilidades; [o que se precisava era] reconhecer esse potencial e dinamizá-lo". O papel da Governança Solidária Local seria "fazer de cada cidadão um indivíduo protagonista, com um papel importante e insubstituível na promoção do desenvolvimento da cidade", o que nos remete a um sujeito produzido segundo o perfil desejado para o tipo de participação social que a Governança Solidária Local almejava (Prefeitura Municipal de Porto Alegre, 2005b, p. 9).

Assim sendo, com base nas ferramentas teóricas foucaultianas, problematiza-se, neste trabalho, a hipótese de o Estado, na tentativa de formar sujeitos empreendedores, dotados de determinado senso político e capacidade operativa, possa estar atuando como uma espécie de coach, uma vez que se utiliza de estratégias que atuam pedagogicamente sobre os indivíduos, sensibilizando-os, ensinando-os, apontando caminhos e modos de caminhar, isto é, atua sobre a mente dos indivíduos - algo que se restringia aos espaços escolares.

Cogita-se, portanto, a proeminência de um Estado-coach, que assume para si o papel de preparar os sujeitos, produzindo modos de ver, pensar e atuar que sirvam à obtenção de melhores resultados para si e para o contexto de atuação. Trata-se de um tipo de governamentalidade centrada em valores econômicos, que parece visar não apenas ao governo das coisas e dos homens, mas das almas ou mentes, considerando que se ocupa com a produção de subjetividades e/ou identidades. Nesse sentido, pode estar contando com a pressa do sujeito em conquistar um lugar privilegiado no seu contexto de inserção, a qual oportuniza ao Estado atuar de acordo com suas prioridades, conduzindo as condutas dos indivíduos em determinados sentidos e não em outros, impactando no tempo de elaboração do ser sujeito e induzindo-o a uma superficialidade preocupante.

\section{A EMERGÊNCIA DO COACH}

O mercado torna-se cada vez mais competitivo a partir do século XX, quando o liberalismo se vê diante de uma crise significativa, tendo que lidar com o aumento do custo econômico do exercício das liberdades. Nesse novo cenário, o mercado passa a ser a nova referência não somente da economia, mas de todas as demais instâncias sociais e da própria existência individual. A condução de si mesmo no competitivo mercado de trabalho e de capitais estimula uma nova forma de subjetivação na qual o indivíduo não passa de agente econômico. E, "ao constituir-se em referência quase exclusiva, o mercado produz individualizações vulneráveis e suscetíveis a seus 
apelos e estímulos incessantes" (Candiotto, 2010, p. 42). Trata-se da emergência do neoliberalismo e de uma nova governamentalidade que vai brotando e instalando-se aos poucos. Nessa nova ordem:

[...] a noção de Homo economicus se amplia, deixando de abranger apenas uma parte da vida para abraçá-la em sua totalidade; todas as ações dos sujeitos devem ser pautadas por um cálculo que envolve investimentos e suas taxas de retorno. A economia recobre a própria vida, buscando tornar cada indivíduo o empresário de si mesmo. (Saraiva, 2010, p. 129)

O neoliberalismo toma por base a economia de mercado e a partir dela busca explicar relações e fenômenos sociais não considerados, em princípio, genuinamente econômicos. Nesse novo tipo de economia política, Gadelha (2009, p. 144) nos fala que temos duas importantes novidades:

[...] em primeiro lugar, observa-se um deslocamento mediante o qual o objeto de análise (e de governo) já não se restringe apenas ao Estado e aos processos econômicos, passando a ser propriamente a sociedade, quer dizer, as relações sociais, as sociabilidades, os comportamentos dos indivíduos, etc.; em segundo, além de o mercado funcionar como chave de decifração ("princípio de inteligibilidade") do que sucede à sociedade e ao comportamento dos indivíduos, ele mesmo generaliza-se em meio a ambos, constituindo-se como (se fosse) a substância ontológica do "ser" social, a forma (e a lógica) mesma desde a qual, com a qual e na qual deveriam funcionar, desenvolver-se e se transformar as relações e os fenômenos sociais, assim como os comportamentos de cada indivíduo.

Essa forma de governamentalidade neoliberal que se institui sob a influência de uma análise e valores econômicos, acaba migrando para outros domínios da vida social, ganhando um forte poder normativo que "institui processos e políticas de subjetivação e que vem transformando sujeitos de direitos em indivíduos microempresas - empreendedores" (Gadelha, 2009, p. 114). A esse processo o autor denomina cultura do empreendedorismo, um processo no qual as pessoas passam a ver a si mesmas como empresas, sendo, por conseguinte, administradoras de si, gestoras e responsáveis pelo seu desenvolvimento econômico-social - capazes de se autogerir, barganhar, conquistar seu espaço e status.

Instaura-se, portanto, uma ordem social regrada economicamente pelo mercado e cerceada pela valorização da empresa como principal agente econômico. Trata-se de um novo modo de governar que, segundo Gadelha (2009), atende ao chamado capital humano e requer certo nível de emprego, de renda, de saúde da população - isso tudo é necessário para o Estado funcionar. Por conseguinte, surge também a necessidade de indivíduos treinados, aptos a desempenhar o papel de empreendedores de si mesmos. Segundo o sociólogo Oswaldo López-Ruiz (2007, p. 18), "capital humano refere-se a um conjunto de atributos humanos (habilidades, capacidades e destrezas) que, abstraídos das pessoas, podem ser articulados em função de um fim externo a elas". 
Nesse novo cenário, temos, de acordo com Damasceno (s/d., p. 1), a emergência do coaching, um processo de elaboração e busca por metas em que um profissional (coach) ajuda um cliente (coachee) a realizar seus objetivos por meio de técnicas oriundas principalmente de abordagens cognitivistas. O papel do coach seria, conforme nos aponta Wolk (2008), capacitar os outros por intermédio de múltiplas ferramentas, para que se convertam em melhores observadores de si mesmos e do seu mundo de relações, a fim de que possam obter o máximo de rendimento de suas competências e habilidades.

O coach vem complementar o papel da educação naquilo que ela parece não alcançar, naquilo que é mais específico ou pontual, procurando, a exemplo do que ocorre no âmbito corporativo, "ligar a organização aos seus colaboradores para um ambiente harmônico, objetivando o alcance de aspirações e metas" (Reis, 2011, p. 18). De acordo com esse autor, para o desenvolvimento de uma organização, no caso da Governança Solidária Local, de município/Estado, é preciso "capacitar as pessoas em conversações e criar espaços de aprendizagem; uma capacitação na qual mais do que aprender a fazer, pressupõe um aprender a ser" (Reis, 2011, p. 18).

No contexto do neoliberalismo nada escapa à lógica econômica, que atinge todas as esferas. Assim, até mesmo a educação, que deveria atuar como emancipadora, invertendo essa lógica por meio da formação para a consciência crítica e para a desalienação, não consegue se desatrelar desse modus operandi, na medida em que precisa formar sujeitos para atender às exigências do mercado. De acordo com Gadotti (2011), o neoliberalismo concebe a educação como uma mercadoria, reduzindo nossa identidade à de meros consumidores, desprezando o espaço público e a dimensão humanista da educação. Para fugir a essa realidade, seria preciso projetar a educação para "além do capital", para uma práxis transformadora, que permita superar a lógica desumanizadora que tem no individualismo, na competitividade e no lucro seus fundamentos; educar para conscientizar, para desalienar, educar para um outro mundo possível. E educar para esse outro mundo possível seria fazer da educação, tanto formal quanto não formal, um espaço de formação crítica e não apenas de formação de mão de obra para o mercado. Implicaria educar para articular as diferentes rebeldias que negam hoje as relações sociais capitalistas.

Porém, no contexto da Governança Solidária Local, o que se buscava parecia ser justamente o contrário, pois, conforme consta no documento de referência do Programa de Governança Solidária Local (Prefeitura Municipal de Porto Alegre, 2005a, p. 13), a ideia era "avançar para formas menos adversarias e mais cooperativas" de democracia participativa, em que "a influência e o exercício de controle dos munícipes se desse de forma mais proativas e propositivas ao invés de apenas reativas e reivindicativas". No que se refere ao aspecto educativo, capacitava para além do ambiente corporativo, pois almejava uma rede ampla de governança solidária (ou seria de agregados?).

Não interessava à Governança Solidária Local "desperdiçar o potencial das comunidades e dos indivíduos", e sim "incorporar o potencial da sociedade para descobrir e desenvolver os seus próprios ativos e dinamizar as suas potencialidades" (Prefeitura Municipal de Porto Alegre, 2005a, p. 13). Em vez de entrar em uma luta demandante para arrancar do Estado determinada ação ou serviço, os sujeitos 
deveriam "assumir responsabilidades e agregar competências inéditas; mobilizar e alavancar recursos novos, que não podem ser captados como (ou da) receita fiscal, mas que devem ser encontrados na base da sociedade" (Prefeitura Municipal de Porto Alegre, 2005a, p. 13), estando aí intrínseca não apenas uma economia de governo, mas também uma intencionalidade pedagógica na medida em que seria necessário sensibilizar e capacitar os sujeitos para o tipo de democracia que se pretendia colocar em prática.

Trata-se de uma governamentalidade que busca programar estrategicamente as atividades e os comportamentos dos indivíduos; que busca "programá-los e controlá-los em suas formas de agir, sentir, pensar, e de situar-se diante de si mesmos, da vida que levam e do mundo em que vivem, através de processos e políticas de subjetivação" (Gadelha, 2009, p. 151). Nessa perspectiva, o que muda não é apenas o modo de conduzir o Estado, mas também o modo de governar corpos e almas, à medida que atua sobre a mente dos indivíduos, governando e fazendo governar.

Daí a prerrogativa da emergência de um Estado-coach, que se ocupa da capacitação dos sujeitos que atuarão na disseminação do programa, na articulação de redes comunitárias de governança e na proposição e atingimento de metas de inclusão social. Um sujeito que se quer que seja solidário, cooperativo, proativo e, sobretudo, empreendedor, mas que deverá atuar no âmbito da coletividade, em sinergia com as causas da sua comunidade que, no contexto da Governança Solidária Local, são postas como causas de legitimidade social. Ao atuar em parceria com o governo na busca do desenvolvimento local, o sujeito estaria assumindo uma atitude de cogestão.

No caso deste trabalho, o que se pontua não é o combate à prática de coaching, mas a necessidade de tomá-la com certo estranhamento, tendo em vista que, conforme nos alerta Foucault (2004), implicaria a formação de identidades que poderiam ser úteis à ação política, mas que, em contrapartida, engessariam os processos de subjetivação, restringindo as possibilidades de constituir-se de outros modos.

\section{DO GOVERNO DAS ALMAS...}

Para entender um pouco mais sobre as razões que levam à hipótese da emergência de um Estado-coach, torna-se relevante destacar, primeiramente, que o Programa de Governança Solidária Local propunha um modo de governar por meio da articulação de redes sociais de participação política democrática, as quais seriam organizadas inicialmente nas dezessete regiões fiscais abrangidas pelo orçamento participativo e, na sequência, nos bairros e vilas. Por meio dessas redes de base territorial, as ações de governo e as iniciativas da sociedade poderiam ser combinadas em prol do desenvolvimento das pessoas e comunidades que estariam vivendo, morando e trabalhando em todas as comunidades do município.

Segundo consta no documento de referência do Programa de Governança Solidária Local, inicialmente foram capacitados os agentes do governo e da sociedade (supervisores, articuladores, comitês gestores governamentais, gerentes de programas), para cumprir o papel de articuladores e animadores das redes de governança solidária local. 
Em seguida esses agentes se deslocaram para as dezessete regiões escolhidas (que já funcionavam como regiões do orçamento participativo) a fim de montar, em cada região, uma equipe de articulação da rede de governança solidária. Essa equipe, composta de pessoas do governo (nucleadas em um comitê gestor) e da sociedade, dedicou-se a conectar, numa rede de âmbito regional, as principais lideranças governamentais, empresariais e da sociedade civil que atuam na região. Estimava-se que cada rede devesse ter conectados cerca de 1/1.000 habitantes dos bairros compreendidos pela região.

As equipes de articulação começaram então a planejar, participativamente, o futuro de cada região, estabelecendo metas e ações prioritárias. Constituíram comunidades de projeto em torno de futuros desejados e compartilhados e fizeram diagnósticos não apenas das necessidades, mas, sobretudo, dos ativos já existentes, que constituíam potencialidades quase sempre pouco aproveitadas por programas tradicionais de oferta estatal. E tudo isso foi validado por um público maior, que já estava conectado nas redes articuladas em cada região.

As ações prioritárias escolhidas e validadas pela rede constituíram a agenda anual de cada região. Pretendia-se que a agenda fosse realizada/atendida com recursos do governo e, principalmente, da própria sociedade - recursos estes mobilizados e alavancados pelas redes que foram articuladas. E, para que houvesse essa condição, foi celebrado um pacto entre todos os membros da Rede de Governança Solidária Local e todos os parceiros, governamentais, empresariais e da sociedade civil e das demais instituições de apoio e fomento que estivessem/estiveram comprometidos com a realização da Agenda de Prioridades.

Da forma como se propôs a articulação das redes e capacitação dos agentes, poderíamos até cogitar um processo de "coaching sistêmico", na medida em que se capacitam determinados agentes que se encarregam de capacitar e orientar novos agentes ou articuladores das redes. De acordo com o Instituto Brasileiro de Coaching (2016), o coaching sistêmico conduz o cliente no processo para que assim ele mesmo possa ir resolvendo e esclarecendo o tema proposto. Ele leva em consideração as conexões, o relacionamento e os processos de intercâmbio entre indivíduos; entre vivência interna, comportamento e vivência externa; de metas, operações e efeitos. Quanto mais agentes ou articuladores capacitados, maior o alcance do programa e, consequentemente, maior a participação das pessoas e o acesso ao capital social/ humano que se tem em vista.

No contexto da Governança Solidária Local a rede que se tinha em mente articular seria uma rede solidária, cooperativa, multidisciplinar, organizada, que deveria conviver harmonicamente em seus espaços de convivência. Uma rede em que a relação entre governo e sociedade seria cada vez mais "horizontalizada". Porém, a partir do momento em que na rede estariam inseridos os agentes do governo, há que se questionar em que medida essa horizontalidade poderia se efetuar/existir.

Ressalta-se, ainda, que o sentido de solidariedade, de proximidade (e/ou empatia) entre as pessoas (num dado ambiente) pode estar relacionado a um processo que, de acordo com Lazzarato (2006, p. 66), "significa religar as singularidades, homogeneizá-las e fazê-las convergir enquanto singularidades em função de um objetivo comum”, o que 
"Deleuze descreve como um procedimento para juntar os networks e patchworks, os fluxos e os agregados"(Lazzarato, 2006, p. 66). Multidisciplinar, porque não se trata apenas de juntar os iguais, mas sobretudo de localizar as diferenças (aquilo no que cada cidadão ou grupo social tem como potencial e que se torna recurso estratégico para a promoção do que a Governança Solidária Local denomina desenvolvimento sustentável). Porém, na ótica de Lazzarato (2006), uma vez que se verifica a existência da diferença entre as forças (ou pessoas), se ressaltam as relações de poder.

A Rede da Governança não seria constituída apenas por integrantes da comunidade ou do governo. Ter-se-ia nessa rede pessoas de todas as esferas - governamentais, empresariais, institucionais, associativas, comunitárias -, as quais coletivamente fariam um diagnóstico das necessidades e potencialidades locais e/ou regionais, combinariam as ações a serem realizadas (proporiam um plano de ação) e, com base nesses recursos/potenciais, "viabilizariam soluções qualificadas para os problemas locais" (Prefeitura Municipal de Porto Alegre, 2008, p. 5). De acordo com a cartilha da Governança Solidária Local (Prefeitura Municipal de Porto Alegre, 2005b, p. 9), "toda pessoa poderia cooperar, aportando novos recursos, novas habilidades, assumindo responsabilidades".

Trata-se de um discurso pensado para atingir o sujeito, para mostrar que, independentemente de sua origem, classe social, situação financeira, ele teria "condição" de participar ativamente, pois, conforme a cartilha da Governança Solidária Local, o indivíduo poderia dar ideias que só ele teria; poderia fazer coisas que só ele saberia fazer; poderia ajudar a planejar o futuro de sua região ou bairro; e poderia ajudar a antecipar esse futuro desejado, contribuindo com o que pudesse, para realizar as ações da agenda de prioridades de sua região (Prefeitura Municipal de Porto Alegre, 2005b, p. 10).

Mas, para chegar a esse nível de participação, precisaria, conforme Feijó (2008), fazer com que o sujeito percebesse (e assumisse) o seu pertencimento local. Para a autora, a explosão de recursos tecnológicos, cada vez mais disponíveis numa velocidade alucinante, "aponta para o caminho ágil para o acesso ao conhecimento, e a fria e inevitável globalização provoca uma reação importante: o reforço das identidades locais e a necessidade de aproximação das mais diversas tribos" (Feijó e De Franco, 2008, p. 32). E, em contrapartida, precisar-se-ia de capacitação e estímulo de todos os envolvidos, razão pela qual se investia em eventos de capacitação e se dava ênfase em iniciativas e projetos locais.

Entre as estratégias utilizadas pela Governança Solidária Local, destacam-se, além da adoção das Redes de Governança, a edição de alguns materiais utilizados na disseminação do programa, a exemplo do seu documento de referência (Prefeitura Municipal de Porto Alegre, 2005a) e da cartilha da Governança Solidária Local (Prefeitura Municipal de Porto Alegre, 2005b); e, mais adiante, a edição da Revista da Governança, ${ }^{2}$ na qual foram divulgados

2 A Revista da Governança foi editada em 2008 para ser usada no Congresso das Cidades e nela estava posto o escopo do Programa de Governança Solidária Local, destacando o modo de participação social, bem como os projetos bem-sucedidos. 
projetos de iniciativa popular que se destacaram regionalmente e que não apenas colocava em evidência o trabalho realizado no âmbito das comunidades, como, em alguma medida, poderia estar legitimando a proposta da Governança Solidária Local como exemplo de boa prática. Trata-se de materiais de caráter informativo-pedagógico que serviam ao propósito de apresentar a proposta de trabalho da governança solidária e mostrar as formas de participação da sociedade, utilizando-se de uma cadeia enunciativa com poder de convencimento, portanto de ação sobre os sujeitos.

Destaca-se, ainda, o uso do ObservaPOA - Observatório da Cidade de Porto Alegre -, um site por meio do qual se divulgava resultados estatísticos relacionados ao desenvolvimento de cada região. Conforme consta no site, ${ }^{3} \mathrm{o}$ ObservaPOA disponibiliza uma ampla base de informações georreferenciadas sobre o município de Porto Alegre e tem um papel pedagógico e político fundamental. Trata-se de reforçar a identidade do local, promovendo o sentido de comunidade nas pessoas e nas famílias. Disponibiliza também indicadores que sejam capazes de qualificar a gestão participativa valendo-se de três perspectivas: social (impactos na melhoria da qualidade de vida e de convivência das pessoas); gestão (impactos na eficácia, transparência e descentralização da gestão municipal); política (impactos no desenvolvimento democrático e na cidadania; expansão do capital social e resgate da identidade local).

Ao que cabe questionar se ao criar redes "locais" de governança, reforçando o pertencimento dos cidadãos a determinadas comunidades (ou "tribos"), bem como "fazendo ver" o potencial e o desenvolvimento local, não estaria a Governança Solidária Local alimentando a competição entre as comunidades e ao mesmo tempo delimitando os grupos para melhor conduzi-los?

A competição pode ter sido (e estar sendo) utilizada como estratégia para alavancar determinados resultados, ainda que, conforme prega a Governança Solidária Local, o que se quer "não é estimular conflitos" (Prefeitura Municipal de Porto Alegre, 2005b, p. 7), mas "promover a participação democrática dos cidadãos porto-alegrenses em prol do desenvolvimento das pessoas e das comunidades" (Prefeitura Municipal de Porto Alegre, 2005b, p. 3). Assim, dividem-se os grupos no macroterritório para gerar concorrência e os aproxima no microterritório para gerar o sentido de solidariedade, de objetivo comum.

Tais estratégias estariam servindo ao propósito de produzir sujeitos ou, pelo menos, o tipo de sujeito almejado pela Governança Solidária Local: solidário, participativo, parceiro, atuante, empreendedor e corresponsável.

Vivenciamos o que Gadelha (2009) denominou de "cultura do empreendedorismo", a qual teria migrado dos domínios estritamente econômico-empresariais para os demais âmbitos sociais. Uma cultura na qual o indivíduo passa a ser percebido como portador de um self subjetivo que:

3 ObservaPoa - Observatório da Cidade de Porto Alegre. Porto Alegre. Disponível em: $<$ http://www.observapoa.com.br/default.php?p_secao=3>. Acesso em: 3 fev. 2015. 
[...] deve aspirar à autonomia, lutar por realização pessoal em sua vida terrena, interpretar sua realidade e destino como uma questão de responsabilidade individual e encontrar significado na existência moldando sua vida através de atos de escolha. (Rose, 1998, p. 151 apud Rosa e Puzio, 2013, p. 219)

De acordo com Busatto, ex-secretário da Secretaria Municipal de Coordenação Política e Governança Local, a responsabilidade social estaria requerendo a emergência de um "cidadão consciente, comprometido com a sobrevivência e o bem-viver de si próprio, de sua família, de sua comunidade e do Planeta, voltado para as grandes causas públicas com que se debate a humanidade neste período de transição de séculos" (Busatto, 2008, p. 14). Destaca, ainda, que o acesso aos meios de comunicação e informação está produzindo um cidadão "inteligente, conectado com sua comunidade real e virtual, bem informado, reflexivo, ativo diante dos desafios que a vida lhe coloca, empreendedor e criativo, disposto ou já exercendo atividades cívicas" (Feijó e De Franco, 2008, p. 15), e esse cidadão tornou-se peça-chave para a idealização e implementação de ações de governança, pois, além de estar imbuído de uma consciência ética e moral, ele detém capacidades e potencialidades que podem ser úteis para a promoção de um ambiente e de uma cultura política de cooperação em busca do bem comum, o que nos remonta a um sujeito produzido. O que temos parece ser o que Gadelha (2009) posiciona como uma opção, alternativa ou técnica dos governantes em relação aos governados; uma forma de neoliberalismo ancorada na teoria do capital humano fundada por Theodore Schultz e Stigler.

De acordo com o documento de referência do Programa de Governança Solidária Local, entre os objetivos do programa e os resultados esperados estariam: implantar a Governança Solidária Local; implantar sistema de monitoramento e avaliação das ações da Governança Solidária Local e do Programa Integrado de Inclusão Social (infância/adolescência, saúde, mulher, segurança e combate à pobreza) nas dezessete regiões; e promover a sensibilização, capacitação e atualização (permanente) dos diferentes sujeitos envolvidos no Programa de Governança Solidária Local.

No que se refere a esse último, a ideia seria municiar os sujeitos com "ferramentas" ditas "apropriadas" ao exercício da democracia pautada em sua proposta, ou seja, para atuar como cogestores na busca de soluções para o desenvolvimento local. Trata-se, segundo Saraiva e Veiga-Neto (2009, p. 191), de uma concepção de trabalho que “já não prioriza o corpo e seus movimentos mecânicos, mas a alma e o seu poder criativo; um trabalho que cada vez ocupa mais destaque e se torna um modelo desejável"; Lazzarato e Negri (2001) chamaram de "trabalho imaterial; intangível; que já não pode ser mensurado em termos de hora-homem; que já não está limitado ao espaço da empresa, nem à jornada de trabalho" (apud Saraiva e Veiga-Neto, 2009, p. 191).

A "sociedade civil" não seria aqui, segundo nos colocou Lazzarato (2008, p. 43), "o espaço onde se fabrica a autonomia em relação ao Estado, mas o correlativo das técnicas de governo". O Homo economicus parece estar sendo entendido como "um certo tipo de sujeito" que, de acordo com Lazzarato (2008, p. 44), "permitiria a uma arte de governar de se limitar, de se regrar segundo princípios da economia e de definir uma maneira de 'governar o menos possível"'. 


\section{CONSIDERAÇÕES FINAIS}

Segundo Castells, "as mudanças fundamentais na sociedade são as que se produzem na mente das pessoas. É aí que surge a mudança: quando as pessoas mudam sua forma de pensar e, portanto, de atuar". ${ }^{4} \mathrm{O}$ século XXI, caracterizado por promover mudanças rápidas e intensas em todos os domínios da vida, também deve agregar, de acordo com Reis (2011), as relações cotidianas, baseadas na observação própria e na do outro, não como espectador, mas como referência do desenvolvimento das habilidades. E quem responde a esse chamado é o coach, que seria "mais do que um facilitador", elevando-se ao patamar de "norteador da capacidade criativa destinada à execução com perícia, a fim de contribuir para o fortalecimento da prática transformadora" (Reis, 2011, p. 11).

Ao assumir para si o papel de capacitar os sujeitos para a concretização de mudanças e desenvolvimento local, a Governança Solidária Local leva ao entendimento de que teria, a exemplo da escola, legitimidade para exercer essa função, uma vez que estaria atuando em parceria com a ONU para o cumprimento das metas do milênio. Teria como função estratégica dominante, segundo consta na Revista da Governança (Prefeitura Municipal de Porto Alegre, 2008), o "desenvolvimento local" num "horizonte estratégico de 10 anos", que coincidiria com o prazo para o alcance das Metas de Inclusão Social da Prefeitura de Porto Alegre, sintonizadas com as Metas do Milênio da Organização das Nações Unidas $(\mathrm{ONU})$, entre as quais:

Acabar com a fome e a miséria; Educação básica e de qualidade para todos; Igualdade entre sexos e valorização da mulher; Reduzir a mortalidade infantil; Melhorar a saúde das gestantes; Combater a Aids, a malária e outras doenças; Qualidade de vida e respeito ao meio ambiente; Todo mundo trabalhando pelo desenvolvimento. (Prefeitura Municipal de Porto Alegre, 2008, p. 8)

Ao se posicionar como parceira da ONU, organização de referência mundial na defesa dos direitos humanos e na busca da paz, em alguma medida a Governança Solidária Local produz, distribui, faz circular a ideia de que sua proposta de ação se sustenta em práticas reconhecidas mundialmente, as quais estariam lhe servindo como diretriz ao mesmo tempo em que poderiam estar legitimando as estratégias adotadas para o governo não apenas das coisas e dos homens, mas das mentes, produzindo modos de ser, pensar e atuar necessários à manutenção do poder. Nesse sentido, conforme apontado anteriormente, Foucault (2004) nos alerta que, embora as identidades possam ser úteis na ação política, elas acabam engessando os processos de subjetivação, restringindo as possibilidades de constituir-se de outros modos.

4 Manuel Castells. Se um país não quer mudar, não é a internet que irá mudá-lo. Folha de S. Paulo, São Paulo, 21 set. 2010. Entrevista. Disponível em: <http://www1.folha.uol. com.br/fsp/poder/po2109201022.htm>. Acesso em: 23 dez. 2017. 


\section{REFERÊNCIAS}

Busatto, C. A essência da Governança Solidária Local. In: FEIJÓ, J.; DE FRANCO, A. (Orgs.). Olhares sobre a experiência da Governança Solidária Local de Porto Alegre. Porto Alegre: EDIPUCRS, 2008. p. 14-17.

Candiotto, C. A governamentalidade política no pensamento de Foucault. Revista Filosofia, São Leopoldo: Unisinos, p. 33-43, jan./abr. 2010. Disponível em: <http:// revistas.unisinos.br/index.php/filosofia/article/view/4632/15198-1>. Acesso em: 12 fev. 2018.

Damasceno, B. A sociedade contemporânea e seus meios de competência: uma crítica ao coaching à luz da teoria psicanalítica. [S.l: s.n.]: s/d. Disponível em: <http://www. psicanalise.ufc.br/hot-site/pdf/Mesas/06.pdf>. Acesso em: 10 jan. 2015.

Feijó, J. Retrospectiva: uma história vivida. In: Feijó, J.; De Franco, A. (Orgs.). Olhares sobre a experiência da Governança Solidária Local de Porto Alegre. Porto Alegre: EDIPUCRS, 2008. p. 19-39.

Feijó, J.; De Franco, A. (Orgs.). Olhares sobre a experiência da Governança Solidária Local de Porto Alegre. Porto Alegre: EDIPUCRS, 2008.

Foucault, M. Michel Foucault, uma entrevista: sexo, poder e a política da identidade. Entrevista com B. Gallagher e A. Wilson. Revista Verve, São Paulo: Verve, n. 5, p. 260-277, 2004. Disponível em: <http://revistas.pucsp.br/index.php/verve/article/ viewFile/4995/3537>. Acesso em: 11 jun. 2015.

. Vigiar e punir: nascimento da prisão. Tradução de Raquel Ramalhete. 38. ed. Petrópolis: Vozes, 2010.

GadelHa, S. Biopolítica, governamentalidade e educação: introdução e conexões, a partir de Michel Foucault. Belo Horizonte: Autêntica, 2009.

Gadotti, M. Novas perspectivas para a educação. Revista Pátio, Porto Alegre: Grupo A, n. 41, s/p. fev./abr. 2011. Disponível em: <http://www.grupoa.com.br/revista-patio/ artigo/6692/novas-perspectivas-para-a-educacao.aspx>. Acesso em: 15 dez. 2014.

GArcía, I. Do capital humano ao capital social: o enfoque de redes organizacionais na gestão de pessoas. Disponível em: <http://www.administradores.com.br/artigos/ cotidiano/do-capital-humano-ao-capital-social-o-enfoque-de-redes-organizacionaisna-gestao-de-pessoas/34238/>. Acesso em: 12 fev. 2018.

Hoss, O. et al. Gestão de ativos intangíveis: da mensuração à competitividade por cenários. 1. ed. São Paulo: Atlas, 2010.

Instituto Brasileiro de Coaching. O que é coaching sistêmico? [S. 1.], 13 abr. 2016. Postado por José Roberto Marques. Disponível em: <http://www.ibccoaching.com.br/ tudo-sobre-coaching/o-que-e-coaching-sistemico/>. Acesso em: 10 fev. 2015.

Lazzarato, M. As revoluções do capitalismo. Rio de Janeiro: Civilização Brasileira, 2006. Biopolítica/bioeconomia. In: PAssos, I. C. F. (Org.). Poder, normalização e violência: incursões foucaultianas para a atualidade. Belo Horizonte: Autêntica Editora, 2008. p. 41-52. 
Lazzarato, M.; Negri, A. Trabalho imaterial e subjetividade. In: Trabalho imaterial. Rio de Janeiro: DP\&A, 2001. p. 25-42.

López-Ruiz, O. Os executivos das transnacionais e o espirito do capitalismo: capital humano e empreendedorismo como valores sociais. Rio de Janeiro: Azougue Editorial, 2007.

Prefeitura Municipal de Porto Alegre. Governança Solidária Local: documento de referência. Porto Alegre: Secretaria de Coordenação Política e Governança Local, 2005a. . Governança Solidária Local: Programa de Governança Solidária Local. Porto Alegre: Secretaria de Coordenação Política e Governança Local, 2005b.

. Revista da Governança. Porto Alegre: Secretaria de Coordenação Política e Governança Local, 2008.

ReIs, H. Coaching ontológico: a doutrina fundamental. Brasília: Thesaurus, 2011.

Rosa, P. O.; Puzıo, M. Governamentalizando o empreendedorismo de si: como as "psicociências" fomentam a produção do Homo economicus. Revista Sociologias Plurais, Curitiba: UFP, v. 1, n. 2, p. 216-229, 2013. Disponível em: <https://neip.info/novo/ wp-content/uploads/2015/04/rosa_puzio_2013.pdf>. Acesso em: 12 fev. 2018.

Saraiva, K. Formação de professores nas tramas da rede: uma prática de governamentalidade neoliberal. Em Aberto, Brasília: INEP, v. 23, n. 84, p. 123-137, nov. 2010. Disponível em: <http://emaberto.inep.gov.br/index.php/emaberto/article/ view/2265>. Acesso em: 23 dez. 2017.

Saraiva, K.; Veiga-Neto, A. Modernidade líquida, capitalismo cognitivo e educação contemporânea. Revista Educação E Realidade, Porto Alegre: UFRGS, v. 34, n. 2, p. 187-202,2009. Disponível em: <http://www.seer.ufrgs.br/educacaoerealidade/article/ viewFile/8300/5538>. Acesso em: 20 nov. 2014.

Wolk, L. A arte de soprar brasas em ação. Rio de Janeiro: Qualitymark Editora, 2008.

\section{SOBRE A AUTORA}

Clarice Antunes do Nascimento é mestre em educação pela Universidade Luterana do Brasil (ULBRA). Professora da mesma instituição. E-mail: claricen@gmail.com

Recebido em 4 de novembro de 2015 Aprovado em 25 de maio de 2016 